\title{
Technology and the Professional Development of Teachers: A Proposed Integrated Model of Technology Adoption (IMTA)
}

\author{
Dr. Azzah Alghamdi \\ Education Administration, 4251, Aldahran street, Yanbu Alsinayah, Saudi Arabia
}

\begin{abstract}
The professional development of teachers is an essential issue that should be considered to ensure a good quality of active lessons and therefore, improve student learning. This paper was formed based on a $\mathrm{PhD}$ study that investigated teachers' use of the Interactive Whiteboards (IWBs) and their training needs in Saudi Arabia. Seven female teachers were observed when using IWBs in their lessons and interviewed. This paper mainly discussed and compared three models of professional development in using technology which are: Burden (2002), Beauchamp (2004), and Concerns-Based Adoption Model (CBAM) (Hall and Hord, 2006). As a result, a new model called the Integrated Model of Technology Adoption (IMTA) was produced based on the outcomes of the current study and was also inspired by Beauchamp model (2004).
\end{abstract}

Keywords: Effective use of IWBs; Professional Development of Teachers; Integrated Model of Technology Adoption.

DOI: $10.7176 / \mathrm{JEP} / 11-20-02$

Publication date:July $31^{\text {st }} 2020$

\section{Introduction}

There is an inevitable effect of technology in both the teaching (Bennett and Lockyer, 2008; Manny-Ikan et al., 2011) and learning processes (Elaziz, 2008; Slay et al., 2008). According to Wood and Ashfield (2008), many opportunities can be offered to teachers when new technologies are introduced in classrooms, and this can lead to enhancing their teaching abilities as well as improving their creativity. Therefore, incorporating new kinds of technology into classes is regarded as a vital issue for all teachers in the twenty-first century (Brooks-Young, 2007). However, Dawes (2000) stated that difficulties could appear when using technologies in classrooms as instructive tools. In the same view, Schmid (2006) reported that introducing innovative technologies in schools could create conflict and problems, and consequently, instructors and learners could be affected.

Thus, teacher training should be considered when using IWBs (Hall and Higgins, 2005; Wall et al., 2005) to improve the quality of their teaching (Compeau and Higgins, 1995; Turel and Demirli, 2010). Indeed, providing educators with appropriate skills and approaches to face technology obstacles is essential for more effective use of technology (Kopcha, 2010). Educators need adequate preparation in how to use IWBs in classrooms to protect them from failure and embarrassment when difficulties occur because of the inappropriate use of these technologies; such frustration could impact learning development (Hall and Higgins, 2005).

The process of teacher improvement when using technology has been explored by several studies (Becker and Ravitz, 2001; Burden, 2002; Beauchamp, 2004; Adams, 2005; Holmes, 2009; Lai, 2010). These studies concentrate on the importance of teachers' improvement in both technical and educational skills, as well as students' use of technology. In terms of interactive whiteboard use, they agreed that new IWB users should have regular and constant training in their use. Furthermore, according to Becker and Ravitz (2001), advanced courses should be progressively delivered during the year by educational leaders, who also offer equipment and time for teachers to practise with these technologies. Indeed, educators usually have different ways and speeds in improving their skills; therefore, they need a comfortable and helpful environment (Beauchamp, 2004).

Additionally, Glover and Miller (2001) state that there are limited training programs for teachers in particular subjects because the focus of IWB suppliers is usually on improving teachers' technical abilities in using the equipment and software. Therefore, the professional development of teachers is an essential factor in ensuring the production of active lessons (Hall and Higgins, 2005; Glover et al., 2007; Holmes, 2009; Torff and Tirotta, 2010). Consequently, appropriate training should be introduced so that educators can use IWBs effectively for learning.

Moreover, in addition to formal training courses, teachers need continued and individually designed training, through which more experienced users of IWBs collaborate with beginner teachers (Glover and Miller, 2001). According to Windschitl and Sahl (2002), communal preparation time with colleagues could be essential in the effective use of technology. In the same view, Levin and Wadmany (2008) state that holding dialogues with colleagues, as well as cooperative thinking developments seem to be beneficial for the best use of technology. Therefore, teacher professional development models have been outlined in several studies to improve teachers' technical and pedagogical skills. Consequently, by doing this, teachers might overcome unexpected technological challenges. 


\section{Teacher Professional Development Models}

\subsection{Burden's (2002) model}

This model was outlined by Burden in a two-year research project examining the actual use of IWBs in schools. The data were gathered through questionnaires and interviews, and by observing two hundred instructors using IWBs in their lessons. This model consisted of three phases when IWBs were used by both the teachers and students in the project: infusion, integration, and transformation. In each stage, schools have specific features, as identified by Burden (2002). In the first stage of improvement (infusion), IWBs were often installed in ICT rooms, and they were usually used as presentation tools. A lack of interaction in classrooms was also noticeable, as was the fact that students in this stage were more passive. Importantly, combining IWBs within the curriculum was not considered at this stage.

However, schools in the integration stage of improvement had successfully established the use of IWBs. They made more effort and time to create suitable strategies which combined the new technology with the syllabus or curriculum. Therefore, IWBs in this stage are described as curriculum tools rather than isolated tools in ICT rooms. Additionally, IWBs are used to enhancing student participation, in which a broader variety of tools is used.

Significant changes related to the use of IWBs identified in the transformation stage because here, interactivity has been considered. IWBs in this stage are used as interactive tools rather than presentation tools, and most classrooms have them installed. Students are actively participating in classroom activities where they use new technologies to build their knowledge. Moreover, different types of multimedia resources are also utilized in this stage.

\subsection{Beauchamp's (2004) model}

This model consists of five phases of instructor and student progress. It specially classifies teachers and learners based on the level of IWB features and activities used in classrooms, and, therefore, these five stages describe the change from novice user of IWBs to the synergistic user. In other words, according to Beauchamp (2004, p. 330), there are five kinds of users "black/whiteboard substitute; apprentice user; initiate user; advanced user; and synergistic user." Beauchamp suggests that the interactive whiteboard moves from being a "passive tool" that is only controlled by the teacher to an "active tool" in learning for students and teachers to interact and build meaning (Beauchamp, 2011).

Black/whiteboard substitute is the first phase in this model, where the IWB is used as a passive tool that is only used by the teacher as an alternative tool for the traditional white/blackboard, on which they write and draw. In this phase, teachers do not make any changes regarding their approach. In the second phase, apprentice user, teachers employ a variety of computer skills and allow their students to use the board themselves as part of prearranged activities within lessons. Students in this stage learn to write, highlight, and drag items on the board. However, the direction of these lessons is still linear. Moreover, teachers widely used PowerPoint to structure their lessons and present clip art and pictures. However, there is limited use of the Internet as well as the external material in this stage.

In the third phase, initiate user, the teacher has "an awareness of the potential of the IWB to change and enhance practice" (Beauchamp, 2004, p. 338). Therefore, teachers plan their lessons for more student use of the IWB as an essential factor in improving their learning. Teachers in this stage start to use a wider range of computer skills, such as maximising and minimising files, opening multiple programs and stored files, and organising folders. PowerPoint files may be used with more effects, such as sound files. Moreover, teachers use external resources and can import files from the Internet. In the fourth phase (advanced user), teachers concentrate on discovering the effect of using IWBs on their teaching and student learning rather than technical skills (Beauchamp, 2004). IWBs in this stage have become an "active tool" in learning (Beauchamp, 2011) to be used by both teachers and students. Students in this stage have more power to use IWBs in lessons frequently and confidently. They can import scanned images, use video clips, use sound files and external resources, develop their own material, and use hyperlinks and websites.

Both students and teachers indicated significant levels of proficiency at the highest level, synergistic user, of the model of Beauchamp (2004, pp. 343,344), who said that:

A synergistic user demonstrates an intuitive interaction with technology, which facilitates a fluid lesson structure. Both teacher and pupils are able to construct meaning and dictate the direction, momentum and scale of the next step in the lesson, although the teacher retains control of the central theme, which is dictated by the learning objective of the lesson.

When students interact with IWBs, according to Beauchamp (2004), this could create an environment where students are the centre of the learning process. Whereas teachers, in this case, are classified in more progressive phases of using IWBs. Advanced teachers were more effective at using IWBs than novice teachers. This possibly because progressive teachers usually use high-scale features of IWBs, in an interactive approach, to present their lessons when communicating with IWBs; in contrast, beginner teachers use IWBs as an ordinary 
whiteboard (Beauchamp, 2004).

The majority of educators' skills in this study were developed when using IWBs frequently, and they reported that their colleagues had trained them to use IWBs. Thus, IWBs certainly might support cooperation between teachers. However, teachers could not enable cooperative learning among students when using IWBs in their lessons. Although IWBs help teachers to manage their lesson time, most teachers reported that they did not allow students to use IWBs because of limited lesson time. According to Beauchamp (2004), training large numbers of educators in the initial basic use of IWBs could be valuable. Then, these educators should have adequate time to integrate their acquired training skills into their lessons and develop confidence in the effective use of IWB features. He added that teachers would allow students to participate more in their lessons when their confidence improves; consequently, in this case, students will become more confident in using IWBs by themselves (ibid.). As seen above, these two models concentrate on both teachers' and students' use of IWBs. Thus, the three phases of the Burden's (2002) model could be linked to the five stages of the Beauchamp's (2004) model, as indicated in Figure 1.

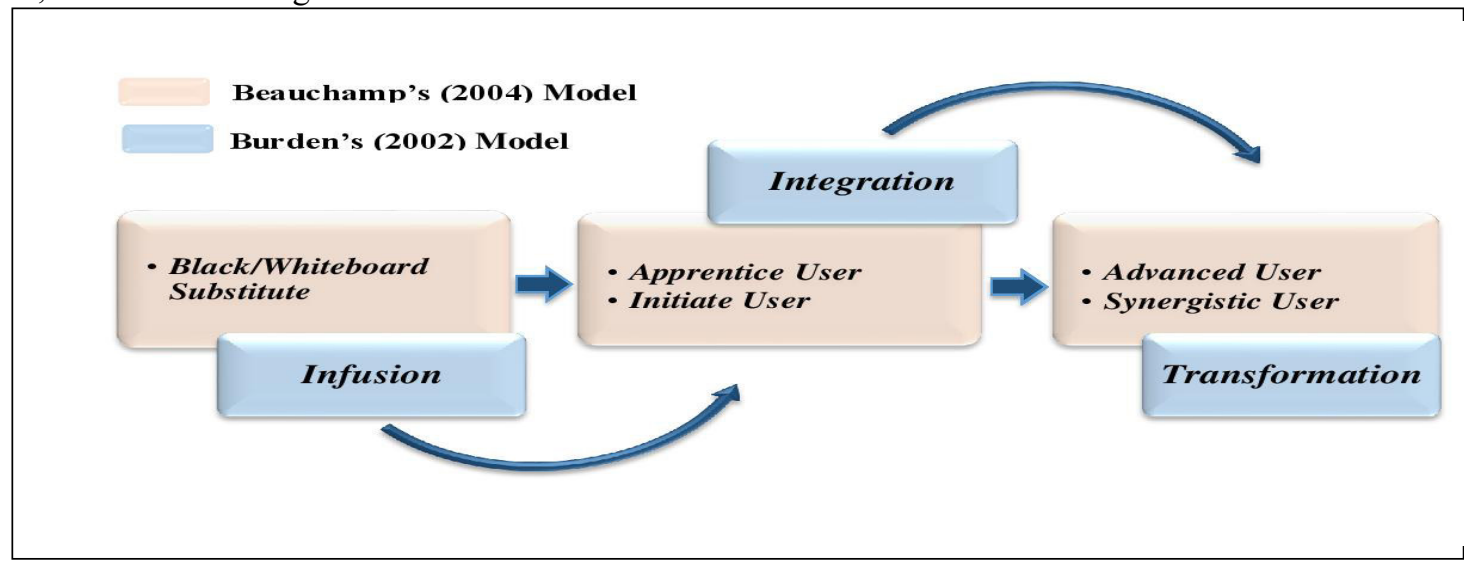

Figure 1. Burden's (2002) and Beauchamp's (2004) models

\subsection{Concerns-Based Adoption Model (CBAM)}

The Concerns-Based Adoption Model (CBAM) is used to assess changes in a curriculum and concentrates on how individuals behave and respond to these reforms (Hall and Hord, 2006). In this model, teachers' interests, concerns, and needs are mainly linked to their professional development in using technology. This model, according to Anderson (1997), is regarded as one of the more theoretically and practically strong models to investigate change. It was devised firstly by Fuller (1969) then at the beginning of the 1980s it was further developed by investigators at Texas University at Austin. It consists of three dimensions that work as lenses through which to understand the process of a change as practised by both individuals and groups. These three dimensions are Stages of Concerns ( $\mathrm{SoCS}$ ), which focus on individuals' feelings, anxieties and views towards applying the change in their context, Levels of Use (LoU), which measure the behavioural sides of change, and Innovation Configurations (ICS), which define the different methods and approaches that teachers apply when using innovations.

The CBAM model considers that the change is not framed as a sudden event but usually occurs as a process through which individuals move. This process consists of stages of concerns as well as various levels of use (Hall and Hord, 2006). Although the CBAM model involves seven stages of concerns, teachers move through these stages in different ways and speeds (ibid.). However, the change may be affected negatively, for example, if teachers do not have enough time in the personal stage or they skip this crucial phase (Khoboli and O'toole, 2012). Similarly, individuals move through the CBAM levels of use at different rates and methods (Hall and Hord, 2006).

There are seven Stages of Concerns (SoCs) in the CBAM model which determine teachers' progress before technologies can be successfully integrated into their lessons. These stages are awareness, informational, personal, management, consequence, collaboration, and refocusing (Hall and Hord, 2006). In the unconcerned stage, teachers may be conscious of new technologies and have little information on how to use them. Therefore, they do not respond or take action at this stage, which is recognised as unrelated-concerns (George et al., 2006). In the informational stage, teachers show an interest in learning how to use new technologies by asking other teachers or searching websites. After this, teachers move toward looking for the effects of technologies on themselves in the personal stage, and decide if these technologies will be helpful in teaching their lessons. The informational and personal stages were categorised, according to George et al. (2006), as personal or selfconcerns. When teachers find these innovations are valuable, they enter the fourth period of change called the management stage. In this stage, teachers learn how to use and employ technologies in their lessons and how to 
solve the difficulties they encounter when using innovations. The management stage is known as task-concerns (ibid.).

When teachers succeed in the management of the innovation, their focus may move to the consequence stage, in which teachers reflect on their methods of using new technology and evaluate its effects on their teaching and their students. When the impacts of technology on the delivery of content are valuable, teachers keep using the technology and may move on to the sixth stage called the collaborative stage. Educators in this stage are distinguished by high enthusiasm for employing innovations in their lessons. They tend to be supporters of the technology and communicate with their colleagues about what they are doing. Finally, in the refocusing stage in the CBAM model, educators are looking for new and effective ways of using technologies in their teaching. By doing this, they seem to achieve high levels of technology usage. The consequence, collaborative, and refocusing stages are called impact-concerns (ibid.). As seen above, four, comprehensive stages of concerns were identified by George et al. (2006). These are unrelated, self, task, and impact concerns.

Considering the CBAM Levels of Use (LoU), these concentrate on the general behaviour of teachers when implementing innovations in classrooms. This is in contrast to the Stages of Concerns (SoCs), which focus on the attitudes of the educator toward a change. Eight levels define the LoU framework: non-user, orientation, preparation, mechanical, routine, refinement, integration, and renewal (Loucks et al., 1975). Progress in this framework is determined by teachers' decisions and conforming behaviours in applying innovations in classrooms (Anderson, 1997).

At the non-user level, teachers have little information about innovation and no plans to implement it (Anderson, 1997). Teachers move to orientation level when they decide to search for information about the innovation, but have still not decided to apply it (ibid.). Teachers enter the preparation level when they are aggressively arranging to use the innovation, but have also not yet actually started to apply it (ibid.). According to Loucks et al. (1975), the previous three levels (non-user, orientation, and preparation) were categorised as non-users, whereas teachers at the mechanical level start using innovation in classrooms. At this level, teachers need to acquire new teaching skills besides learning technical skills (Anderson, 1997). Indeed, teachers may find difficulties at this level because they work hard to make the innovation more adaptable and easier to use. Therefore, being teacher-centred seems to be more apparent at this level (ibid.). When teachers have regular use of innovations in their lessons with no consideration to change the innovation, they will progress to the routine level, where most teachers remain (ibid.).

However, some teachers may have a more active contribution to evaluating the effects of using the innovation on their students, and they make changes relating to the innovation or their approach. In doing this, their level will develop to refinement level, where a more student-centred approach is apparent about the changes in using innovations (ibid.). Teachers who collaborate with their colleagues are at the integration level, as they seek to improve their use of innovations to achieve student success (ibid.). Indeed, teachers at this level tend to reach a more expansive stage in which they think about how to improve the learning process. Finally, some teachers move to the renewal level, when they find the necessity of significant improvements in the use of innovation or discover other performs (ibid.). The last three levels (refinement, integration, and renewal) were grouped as users (Loucks et al., 1975).

While the third dimension of the CBAM model (innovation configurations) (ICs) describes differences in employment for different instructors when implementing new technology, because they will usually have various methods of practice (Anderson, 1997).

According to Hall and Hord (2006), there is a relationship between the CBAM LoU and SoCs. Individuals in the (non-user) level seem to have more powerful self-concerns, and this will lead to these individuals in the higher levels of use being more likely to have impact concerns. Nevertheless, this association has not been supported by research (ibid.), and educators' concerns (e.g. their feelings, views, and attitudes toward the technology) appear to be essential for designing training programmes. This can enable the successful adoption of technologies and decrease teachers' frustration and conflicts (Surry and Land, 2000; Hall and Hord, 2006). Indeed, teachers have different concerns, as framed by Hall and Hord (2006), about using advanced technologies, and it is normal for people to have various concerns whether positive or negative when dealing with innovation (Holloway, 2003). Therefore, educators are considered the main element in determining the successful implementation of technology in classrooms, in addition to the effective integration of technology in the syllabus (Gatlin, 2004). Thus, if educators are not satisfied with their training programme, they are unlikely to be able to integrate the new skills in their teaching methods effectively.

The CBAM model has been described as a well-known tool for allowing participants to recognise reforms in educational situations, and therefore it has widespread approval in the field of educational research because it concentrates on the concerns of individuals toward using innovations (Newhouse, 2001; Adams, 2002). In other words, according to Hall and Hord (2006), the fundamental assumption of this model is that an essential aspect of any revolution procedure is the individual involved because institutions cannot make any improvements before the individuals involved improve. The CBAM model enables the investigation of the different levels of 
individuals' concerns and their use in the process of the adoption of advanced technologies, through investigating what is defined by SOCs and LoU (Hall and Hord, 2006).

Studies have found that the characteristics of individuals, such as gender, age, amount of training, teaching subject, and availability of support, may affect their level of concern. Additionally, these studies have reported useful information for improving and supporting institutions and individuals when adopting new technologies (Adams, 2002; Rakes and Casey, 2002). Consequently, individuals' concerns will have different levels of power based on these characteristics. For instance, the individuals' contribution to professional development programmes that relate to advanced innovations is one of these factors that determine the individuals' levels of concern (Adams, 2002; Crawford, 2003; Hall and Hord, 2006). When people become more trained in using advanced technologies, their concerns will significantly change (Hall and Hord, 2006). Thus, the CBAM model seems to be useful in understanding the process of change in using technologies, and in designing effective strategies for change, such as workshops or action research programmes (Khoboli and O'toole, 2012). Moreover, it affords valid and reliable methods of evaluating the effect of change relating to the use of innovations (Hall and Hord, 2006).

\subsection{The CBAM Levels of Use and Beauchamp's (2004) Model}

Comparing these two models (see Figure 2) indicates that the black/whiteboard substitute level in Beauchamp (2004) model could be linked to the mechanical LoU, where teachers start using IWBs in classrooms as a presentation tool. In contrast, apprentice and initiate users of Beauchamp (2004) model appear to fit better with the Refinement LoU, where a more student-centred approach appears and teachers focus on both the technical and pedagogical skills of using IWBs. However, both advanced and synergistic users of Beauchamp (2004) model seem more likely to be consistent with the renewal level, which is the highest LoU, in which teachers tend to discover new methods to improve their use of IWBs.

It can be seen that Beauchamp's (2004) model, which consists of five stages, classifies both teachers and students based on their level of using IWB features and activities in classrooms from the simple use to the advanced. However, the LoU only focus on teachers and measures the change in their behaviour when implementing innovations in classrooms from non-users to users, through eight levels. Moreover, Beauchamp's (2004) model did not explicitly consider the frequency of using IWBs. In contrast, teachers' regular use of IWBs is considered in the routine level, which is one LoU. Although there are some indications of improving teachers' skills in using IWBs through collaborations with colleagues in Beauchamp's (2004) study. However, this model did not clearly involve teachers' collaboration as a categorical level, even though this is found in the CBAM levels of use (the integration level).

Indeed, Beauchamp's framework seems to be a useful tool which allows teachers to map their use of IWBs in five phases across four domains. This model assumes that teachers have IWBs and progress differently through five stages towards the highest level (synergistic user). Moreover, in Beauchamp's study (2004), teachers had been trained for two years to use IWBs and then they practised using these technologies for one year. Therefore, this model could be more appropriate for evaluating teachers' use of IWBs in advanced countries which heavily use IWBs in their classrooms. Since the CBAM model contains three levels (non-user, orientation, and preparation), which teachers go through before using IWBs, the CBAM model may be more effective for evaluating teachers' levels of use in developing countries which have recently started to use IWB technology in their classrooms. As a result, the eight levels of the CBAM LoU model were found more appropriate and fitted with the design of the current study, which mainly focused on teachers' use of IWBs in Saudi Arabia. Therefore, for the reasons addressed above, the researcher decided to employ the CBAM model to classify Saudi teachers' levels when using IWBs. For this study, the CBAM LoU model was used as conceptual lenses and not as practical methodologies, to understand the research findings from logical justifications and enhance the internal validity of this research when comparing the research results with challenging models (Yin, 2003). 


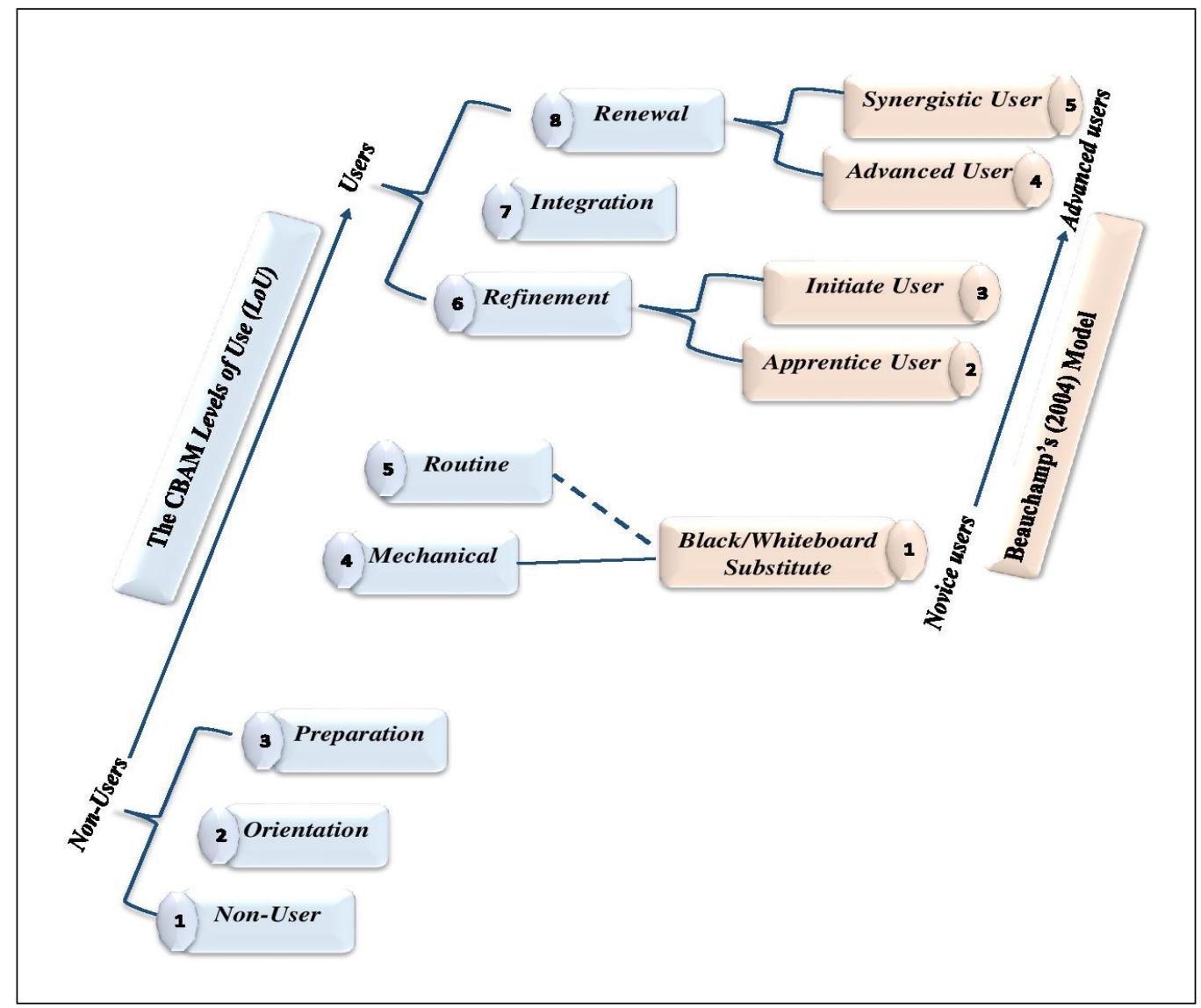

Figure 2. The CBAM Levels of Use and Beauchamp's (2004) Model

\section{Discussion}

Comparing the CBAM levels of Use (LoU) (Hall and Hord, 2006) and Beauchamp's model (2004) indicates that both models consisted of several levels that teachers go through when using technologies. Therefore, both are used to classify teachers' levels when using digital technology. However, when linking the eight levels that define the LoU framework with the five stages of Beauchamp's model (2004) (see Figure 2); the difference between the two models appeared through five levels. These five levels are; non-user, orientation, preparation, routine, and integration. All these levels are explicitly found in the CBAM levels of Use (LoU) as certain levels compared with Beauchamp model (2004).

The CBAM model contains three levels (non-user, orientation, and preparation), which teachers go through before using IWBs. Whereas, Beauchamp's model (2004) focused more on teachers who use this technology. Thus, the CBAM model may be more useful for evaluating teachers' levels of use in developing countries, which have recently started to use IWB technology in their classrooms.

The routine level was indicated in the CBAM model at a higher level than the Mechanical level. Indeed, teachers should use technology regularly and consider daily use as a habit for more effective use of IWBs. Teachers should be encouraged to daily and continuously using technology in their lessons to increase their confidence in using technology (Armstrong et al., 2005). Consequently, this will lead to developing their skills (Glover and Miller, 2001). However, some teachers could not use technologies daily because of their location and lack of access to technology or the nature of the content of lessons. Some expert teachers do not have IWBs in their usual classrooms but in places like a learning resources room. The location of this technology prevents those teachers from daily use, especially in the case of schools with only one learning resources room for all classes. In this case, the classification of teachers' levels based on the CBAM model places those skilled teachers at the lower level (Mechanical level). However, some of those teachers might have sufficient technical and pedagogical skills of using IWBs, where they should be in the higher levels of the CBAM model.

Moreover, according to the findings of this study, three teachers used IWBs differently based on the nature of the topic introduced to their students. Indeed, it appears that these teachers knew what was beneficial for students' learning, leading to the decision of whether to use the IWB or not in their lessons. The teacher, who teaches Islamic sciences, indicated that he used this technology sometimes to teach the Quran lessons. He stated that he preferred to present a consistent reading by himself to his students and then explain its meaning. 
Similarly, the teacher, who teaches students with learning difficulties, indicated that her use of the IWB depends on the nature of the topic introduced to her students. Moreover, when IWBs are placed in laboratories, their use was not consistent in each lesson. Science teachers (17\% of the sample) sometimes prefer to focus on practical experiences during lessons more than demonstrating ideas or concepts on the board. This was confirmed in the current study during the interview as one of the science teachers reported that he sometimes used the IWB in the laboratory.

Thus, I am consistent with Beauchamp's model in that I have not separated the routine level as a distinct level because the daily use of technology could be during any stage whether in the lower or higher levels. Therefore, the routine level might be better indicated implicitly in the model but not as a discrete level that used to classify teachers' levels of use.

Regarding the integration level, based on the findings of the current study, it should be better not located in the higher levels of the LOU framework, but it should be between mechanical and routine levels because some teachers may collaborate with their colleagues at the beginning of using technologies as did by two observed teachers in this study. These two teachers did not use the IWB every day in their lessons because of the location of this technology in a learning resources room. These two teachers reported that they trained through collaboration with the teacher who was responsible for the learning resources room, which is usually found at a high level (the Integration Level). However, inconsistent use of this technology suggests they are best placed at the Mechanical level.

Moreover, some teachers do not collaborate with colleagues during training instead; they relied on different ways to improve their skills, such as the expert teacher who teaches Islamic sciences. This teacher appeared to be working at the Renewal Level, which is the highest level of the CBAM Levels of Use (LoU). She seemed to have skipped the Integration Level because she was trained first in her school and so she relied on herself to improve her use of IWBs. During the interviews, there was no indication of collaboration with colleagues to develop her skills. Thus, this could suggest that the Integration Level of LoU is not an essential stage that teachers must pass through.

Thus, the Integration Level of LoU seems to be better moved to be between mechanical and routine levels of LoU as in the case of the two teachers who teach mathematics or to be not considered as an essential stage as in the case of the teacher who teaches Islamic sciences. However, some expert teachers could also collaborate to discuss using new methods or strategies regarding using IWBs. As a result, the Integration Level could be better placed implicitly during any stage of teachers' levels of use but not as a certain stage similar to Beauchamp' model (2004).

Therefore, the CBAM levels of Use (LoU) (Hall and Hord, 2006) was adapted to provide a new model based on the findings of the current study. This model was also inspired by Beauchamp's model (2004), suggests four potential levels of innovative technology integration. These levels are: non-user, mechanical, refinement, and renewal. This new model can be called the Integrated Model of Technology Adoption (IMTA) (see Figure 3).

\subsection{A proposed Integrated Model of Technology Adoption (IMTA)}

In this model, the three levels (non-user, orientation, and preparation), which were categorised as non-users in the CBAM levels of Use (LoU), were combined as one category level that indicates the situation of teachers who do not using the technology, including having little or enough information about the innovation as well as for deciding to use or not to use the technology. The mechanical, refinement, and renewal levels remained as indicated in the CBAM levels of Use (LoU). The mechanical level, where teachers start using IWBs in classrooms as a presentation tool. The Refinement level, where a more student-centred approach appears, and teachers focus on both the technical and pedagogical skills of using IWBs. The highest level of this model is the renewal level in which teachers tend to discover new methods to improve their use of IWBs. However, the two levels the routine, and integration were found to be suitably indicated implicitly in the IMTA model similar to the Beauchamp's model (2004). The integration may appear at any level starting from the level of non-users, where teachers might discuss some information related to the use of technologies with their colleagues. Whereas, the routine can only appear in the mechanical, refinement, and renewal levels. Thus, the IMTA model can be used to classify the levels of teachers when using educational technologies in classrooms based on four levels: non-user, mechanical, refinement, and renewal. 


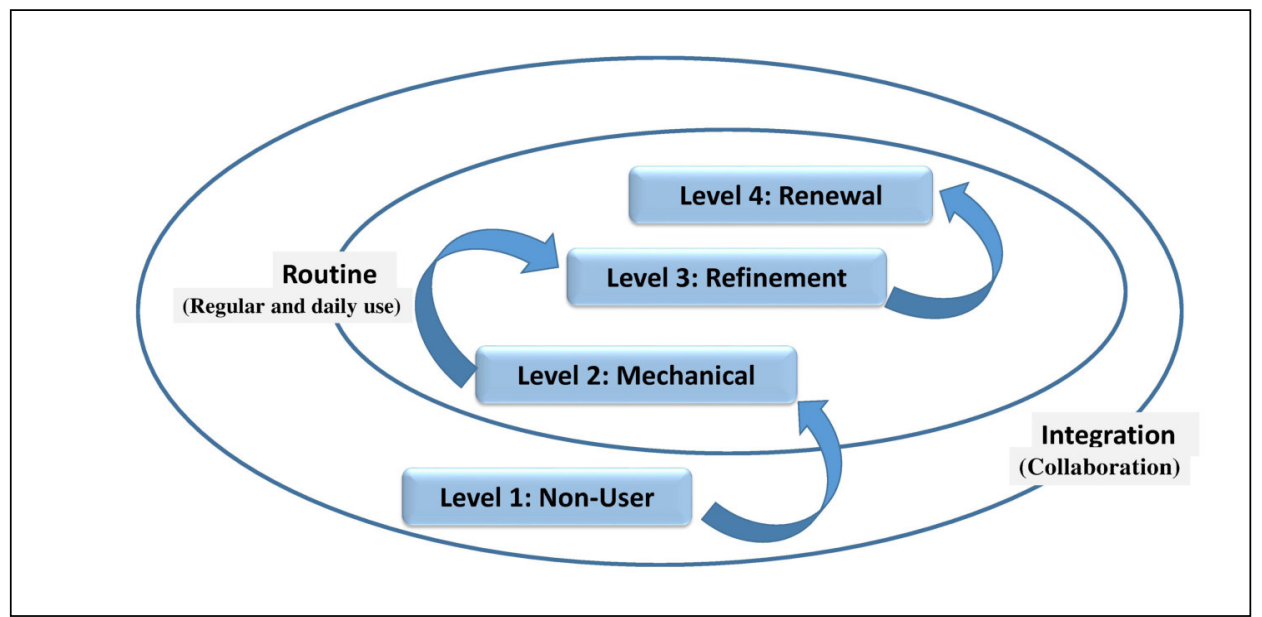

Figure 3. Alghamdi’s Integrated Model of Technology Adoption

\section{Conclusion}

In this paper, the CBAM levels of Use (LoU) (Hall and Hord, 2006) was adapted to provide a new model called the Integrated Model of Technology Adoption (IMTA) based on the findings of the current study and was also inspired by Beauchamp's model (2004), suggests four potential levels of innovative technology integration. These levels are: non-user, mechanical, refinement, and renewal. Thus, the IMTA model can be used to classify the levels of teachers when using educational technologies in classrooms.

\section{Acknowledgements}

I am sincerely grateful for my supervisor (Prof. Steve Higgins) for his great support while conducting this work. Moreover, I would like to show my deepest appreciations to the Department of Education in Jeddah for enabling conducting this study. Special thanks go to my family for constant support and encouragement.

\section{References}

Adams, N.B. (2002) 'Educational computing concerns of postsecondary faculty', Journal of Research on Technology in Education, 34(3), pp. 285 - 303.

Adams, S.T. (2005) ' A strategy for technology training as part of a master's program conducted at a school site', Journal of Technology and Teacher Education, 13(3), pp. 493-514.

Anderson, S.E. (1997) 'Understanding teacher change: Revisiting the concerns-based adoption model', Curriculum Inquiry, 27(3), pp. 331-367.

Armstrong, V., Barnes, S., Sutherland, R., Curran, S., Mills, S. \& Thompson, I. (2005) 'Collaborative research methodology for investigating teaching and learning: the use of interactive whiteboard technology', Educational Review, 57(4), pp. 457-469.

Beauchamp, G. (2004) 'Teacher use of the interactive whiteboard in primary schools: Towards an effective transition framework.', Technology, Pedagogy and Education, 13(3), pp. 327-348.

Beauchamp, G. (2011) 'Interactivity and ICT in the primary school: categories of learner interactions with and without ICT', Technology, Pedagogy and Education, 20(2), pp. 175-190.

Becker, J.H. \& Ravitz, J.L. (2001) 'Computer use by teachers: Are Cuban's predictions correct?', 2001 annual meeting of the American Educational Research Association. Seattle, Washington.

Bennett, S. \& Lockyer, L. (2008) 'A study of teachers' integration of interactive whiteboards into four Australian primary school classrooms', Learning, Media and Technology, 33(4), pp. 289-300.

Brooks-Young, S. (2007) Digital-age literacy for teachers: Applying technology standards to everyday practice. Washington DC: International Society for Technology in Education.

Burden, K. (2002) 'Learning from the bottom up - The contribution of school based practice and research in the effective use of interactive whiteboards for the FE/HE Sector', Making an Impact Regionally Conference. The Earth Centre, Doncaster, UK.

Compeau, D.R. \& Higgins, C.A. (1995) 'Application of social cognitive theory to training for computer skills', Information systems research, 6(2), pp. 118-143.

Crawford, C. (2003) 'Web-enhancing university coursework: An innovative professional development model to support a step-by-step approach towards web-enhancing courses and empowering instructors', International Journal on E-Learning, 2 (1), pp. 5-13.

Dawes, L. (2000) ' First connections: Teachers and the National Grid for Learning', Computers and Education, 33(4), pp. 235-252. 
Elaziz, F. (2008) Attitudes of students and teachers towards the use of Interactive whiteboards in EFL classrooms. Master thesis. Bilkent University, Ankara.

Fuller, F.F. (1969) 'Concerns of teachers: A development conceptualization', American Educational Research Journal, 6 (2), pp. 207-226.

Gatlin, M. (2004) 'Interactive whiteboard system creates 'active classrooms' for rural Georgia school system', The Journal, 31 (6), pp. 50-52.

George, A.A., Hall, G.E. \& Stiegelbauer, S.M. (2006) Measuring implementation in schools: The stages of concern questionnaire. Austin, TX: SEDL.

Glover, D. \& Miller, D. (2001) 'Running with technology: the pedagogic impact of the large-scale introduction of interactive whiteboards in one secondary school', Journal of Information Technology for Teacher Education, 10(3), pp. 257-278.

Glover, D., Miller, D., Averis, D. \& Door, V. (2007) 'The evolution of an effective pedagogy for teachers using the interactive whiteboard in mathematics and modern languages: an empirical analysis from the secondary sector', Learning, Media and Technology, 32(1), pp. 5-20.

Hall, G.E. \& Hord, S.M. (2006) Implementing change: Patterns, principles and potholes. New York, NY: Pearson Education.

Hall, I. \& Higgins, S. (2005) 'Primary school students' perceptions of interactive whiteboards', Journal of Computer Assisted Learning, 21(2), pp. 102-117.

Higgins, S., Falzon, C., Hall, I., Moseley, D., Smith, F., Smith, H. \& Wall, K. (2005) Embedding ICT in the literacy and numeracy strategies : final report. Newcastle: DU. [Online]. Available at: http://dro.dur.ac.uk/1899/.

Holmes, K. (2009) 'Planning to teach with digital tools: Introducing the interactive whiteboard to pre-service secondary mathematics teachers', Australasian Journal of Educational Technology \& Society, 25 (3), pp. 351-365.

Holloway, K. (2003) 'A measure of concern: Research-based program aids innovation by addressing teacher concerns', Tools for Schools, 6(4), pp. 1-2.

Khoboli, B. \& O'toole, J.M. (2012) 'The Concerns-Based Adoption Model: Teachers' Participation in Action Research', Systemic Practice and Action Research, 25, pp. 137-148.

Kopcha, T., J. (2010) 'A systems-based approach to technology integration using mentoring and communities of practice', Educational Technology Research and Development, 58(2), pp. 175-190.

Lai, H.J. (2010) 'Secondary school teachers' perceptions of interactive whiteboard training workshops: A case study from Taiwan', Australasian Journal of Educational Technology, 26(4), pp. 511-522.

Levin, T. \& Wadmany, R. (2008) 'Teachers' views on factors affecting effective integration of information technology in the classroom: developmental scenery', Journal of Technology and Teacher Education, 16(2), pp. 233-263.

Loucks, S.F., Newlove, B. \& Hall, G.E. (1975) Levels of use of the innovation: A manual for trainers, interviewers, and raters. Austin, TX: Research and Development Centre for Teacher Education, University of Texas.

Manny-Ikan, E., Dagan, O., Tikochinski, T.B. \& Zorman, R. (2011) 'Using the Interactive White Board in Teaching and Learning - An Evaluation of the SMART CLASSROOM Pilot Project', Interdisciplinary Journal of E-Learning and Learning Objects, 7(1), pp. 249-273.

Newhouse, C.P. (2001) 'Applying the concerns-based adoption model to research on computers in classrooms', Journal of Research on Computing in Education, 33(5), pp. 1-21.

Schmid, E.C. (2006) 'Investigating the use of interactive whiteboard technology in the English language classroom through the lens of a critical theory of technology', Computer Assisted Language Learning, 19(1), pp. 47-62.

Slay, H., Siebörger, I. \& Hodgkinson-Williams, C. (2008) 'Interactive whiteboards: Real beauty or just "lipstick"?', Computers \& Education, 51(3), pp. 1321-1341.

Surry, D.W. \& Land, S.M. (2000) 'Strategies for motivating higher education faculty to use technology', Innovations in Education and Training International, 37(2), pp. 145-153.

Torff, B. \& Tirotta, R. (2010) 'Interactive whiteboards produce small gains in elementary students' self-reported motivation in mathematics', Computers and Education, 54, pp. 379-383.

Turel, Y.K. \& Demirli, C. (2010) 'Instructional interactive whiteboard materials: Designers' perspectives', Procedia-Social and Behavioral Sciences, 9, pp. 1437-1442.

Rakes, G.C. \& Casey, H.B. (2002) An Analysis of Teacher Concerns toward Instructional Technology. Available at: http://ascilite.org/archived-journals/ijet/v3n1/rakes/ (Accessed: 14 th June 2016).

Wall, K., Higgins, S. \& Smith, H. (2005) 'The visual helps me understand the complicated things': pupil views of teaching and learning with interactive whiteboards', British Journal of Educational Technology, 36(5), pp. 851-867. 
Windschitl, M. \& Sahl, K. (2002) 'Tracing teachers' use of technology in a laptop computer school: The interplay of teacher beliefs, social dynamics, and institutional culture', American Educational Research Journal, 39, pp. 165-205.

Wood, R. \& Ashfield, J. (2008) 'The use of the interactive whiteboard for creative teaching and learning in literacy and mathematics: A case study', British Journal of Educational Technology, 39(1), pp. 84-96.

Yin, R. (2003) Case Study Research Design and Method. California: Sage Publications. 